\title{
Trends in treatments of thyroid disease following iodine fortification in Denmark: a nationwide register-based study
}

This article was published in the following Dove Press journal:

Clinical Epidemiology

\author{
Line Tang Møllehave' \\ Allan Linneberg ${ }^{1-3}$ \\ Tea Skaaby' \\ Nils Knudsen ${ }^{4}$ \\ Torben Jørgensen ${ }^{1,5,6}$ \\ Betina Heinsbæk Thuesen' \\ 'Center for Clinical Research and \\ Disease Prevention, Bispebjerg and \\ Frederiksberg Hospital, Capital \\ Region, Copenhagen, Denmark; \\ ${ }^{2}$ Department of Clinical Medicine, \\ Faculty of Health and Medical \\ Sciences, University of Copenhagen, \\ Copenhagen, Denmark; 3Juliane Marie \\ Centre, Rigshospitalet, Copenhagen, \\ Denmark; ${ }^{4}$ Department of \\ Endocrinology, Bispebjerg University \\ Hospital, University of Copenhagen, \\ Copenhagen, Denmark; ${ }^{5}$ Department \\ of Public Health, Faculty of Health \\ and Medical Sciences, University of \\ Copenhagen, Copenhagen, Denmark; \\ ${ }^{6}$ Faculty of Medicine, Aalborg \\ University, Aalborg, Denmark
}

Correspondence: Line Tang Møllehave Frederiksberg Hospital, Hovedvejen, Entrance 5, Nordre Fasanvej 57,

DK-2000 Frederiksberg, Denmark

Tel +45 38633275

Email line.tang.moellehave@regionh.dk
Background: Long-term iodine exposure may influence the frequency of thyroid disease treatments through fluctuations in thyroid diseases. Yet, the long-term fluctuations in thyroid disease treatments upon iodine fortification (IF) are not fully known. We aimed to examine the development in thyroid disease treatments in Denmark before and following the implementation of IF in 2000.

Methods: Nationwide data on antithyroid medication, thyroid hormone therapy, thyroid surgery, and radioiodine treatment were obtained from Danish registries. Negative binominal regression was applied to analyze annual changes in treatment rates adjusted for region of residence, sex, and age.

Results: Incidence of antithyroid medication transiently increased but fell and reached steady state from 2010 at an incidence rate ratio (RR) of 0.72 (95\% confidence interval [CI] 0.67-0.77) compared to year 2000. Thyroid hormone therapy increased and reached steady state in 2010 at an incidence RR of 1.75 (95\% CI 1.62-1.89) compared to year 2000. Thyroid surgery was constant except for higher rates in 2014-2015, and radioiodine treatment fluctuated with no apparent pattern.

Conclusion: Ten years after IF, a steady state was observed for incident antithyroid medication below the level at IF, and thyroid hormone therapy above the level at IF. Only small changes were observed in thyroid surgery and radioiodine treatment. In the same period, changes in diagnostic and treatment practices and lifestyle factors are likely to have occurred and should be considered when evaluating the effects of IF on treatment of thyroid diseases.

Keywords: iodine, pharmacoepidemiology, thyroid diseases

\section{Introduction}

The incidence of thyroid disease treatments is affected by the population's exposure to iodine over several years, perhaps decades. ${ }^{1}$ Iodine fortification (IF) is implemented worldwide to improve iodine status, ${ }^{2}$ but the long-term development in thyroid disease treatments after IF and the period until a new steady state is achieved remains to be fully established. It is relevant to monitor thyroid disease treatments after IF as part of the evaluation of potential effects of IF on the burden of disease on the population and the health care system.

The incidence of some thyroid diseases (eg, hyperthyroidism) fluctuates promptly and markedly upon IF, ${ }^{3,4}$ while only minor changes over longer time are observed in other thyroid diseases (eg, hypothyroidism).$^{5-7}$ The incidence of treatments might rapidly reflect changes in disease occurrence, whereas the prevalence of medication treatments 
of longer duration is expected to change more slowly. Furthermore, changes in incident thyroid disease treatments are expected to differ between region of residence, sex, and age groups. National voluntary IF of salt with $8 \mathrm{ppm}$ iodine was implemented in Denmark in 1998, but this proved inefficient ${ }^{8}$ and was replaced with mandatory IF of salt with $13 \mathrm{ppm}$ iodine in July 2000. ${ }^{9}$ Eastern and Western Denmark had mild and moderate iodine deficiency (ID) before IF, respectively. After IF, the population iodine intake was adequate but still below the recommended level in specific groups. ${ }^{10}$ Particularly, women had an overall higher risk of insufficient iodine intake and thereby thyroid diseases, and different age groups had been exposed to different durations of ID before IF. ${ }^{11}$

Development in thyroid disease treatment rates does not solely depend on IF. Diagnostic activity, indication for treatment, treatment aims, health care-seeking behavior, diet, alcohol, and smoking may all change over time, and the effect on patterns of thyroid disease treatment must be discussed.

The development in incident thyroid disease treatments after the implementation of IF in Denmark has previously been examined until 2007-2008 but without identification of a steady state. ${ }^{12-14}$ Now, we are able to update with further 6-8 years of data from nationwide registers with complete individual-level information. We previously utilized these data to examine the development in costs of thyroid disease treatment. $^{15}$

We aimed to assess the development in annual rates of incident thyroid disease treatments (antithyroid medication, thyroid hormone therapy, thyroid surgery, and radioiodine treatment) during 1995-2015.

\section{Methods}

\section{Design and study population}

This register-based study included data on all redeemed prescriptions, and in- and outpatient hospital treatments for thyroid diseases in the entire Danish population during 1995-2015. Almost all patients with thyroid diseases are treated in the tax-funded Danish public health care system, and administrative registers contain individual-level information on treatments and demographics. ${ }^{16}$ Linkage between registers is possible via the unique personal identification number assigned to all Danish citizens. ${ }^{17}$

\section{Thyroid medication: antithyroid medication and thyroid hormone therapy} Information on thyroid medication was obtained from the Danish National Prescription Registry, which contains all redeemed prescriptions since 1995. Antithyroid medication and thyroid hormone therapy were identified by the Anatomic Therapeutical Chemical (ATC) classification system codes H03B and H03A, respectively, from 1995 to 2015. Prescriptions of thyroid medication following thyroid surgery or radioiodine treatment were excluded.

Incident use was defined as a minimum of two redeemed prescriptions or 300 defined daily doses (DDD) within 365 days and no redeemed prescriptions of any thyroid medication within the previous 730 days. Incident users were thus only defined from 1997. Persons were defined as incident cases in the year of the first prescription fulfilling these criteria.

Prevalent use was defined as a minimum of two redeemed prescriptions or 300 DDD within 365 days. Persons were defined as prevalent cases in all the years these criteria were met.

\section{Thyroid surgery}

All thyroid surgeries are registered in the Danish National Patient Registry. Data on thyroid surgery were obtained during 1995-2015 by the Nordic Classification of Surgical Procedures codes: 08060-08200 before 1996 and BAA20BAA60(A) after 1996. Surgeries performed in one patient within 30 days were counted as one surgery. Thyroid surgeries classified with a diagnosis of thyroid cancer (ICD-8 and ICD-10 codes: 19399 and DC739) up to 3 months after surgery were excluded.

\section{Radioiodine treatment}

Radioiodine treatments were registered in the Danish National Patient Registry since 2004. Treatments from 2004 to 2015 were identified by the procedure codes BWGGI and WT(F-L)RNJLXX for benign disease. Procedures performed in one patient within 90 days were counted as one treatment. From 1995 to 2003, number of standard doses (600 MBq) used and indication (benign/malignant) were reported from the hospital departments to the National Institute of Radiation Protection. We defined one standard dose as equivalent to one treatment. ${ }^{12}$ This information could not be linked to individual patients, but the location of the treating hospital was used as a proxy for region in the analyses.

\section{Sex, age, and region}

Information on sex, date of birth, and region (moderate and mild ID before IF) was obtained from the Civil Registration System and linked to each redeemed prescription, surgery, and radioiodine treatment. Persons over 100 years were excluded. 


\section{Statistical analyses}

Incidence was calculated as the number of incident users every year per 100,000 person years (PY). PY was calculated as the total population minus the number of prevalent users in the previous year. Period prevalence was calculated as the number of prevalent users every year per 100,000 persons. To adjust for changes in population size and sex and age distribution, the treatment rates were standardized to the population in 2000 by region by multiplying the relative difference in population strata.

Negative binominal regression was applied to estimate the incidence and prevalence rate ratios (RRs) between calendar years. The Wald Chi-square test was used to test for significance. Year 2000 (the year of implementation of mandatory IF of salt with 13 ppm iodine) was used as reference unless otherwise mentioned. The negative binomial regression analyses were performed in the unstandardized population, and the models adjusted for region, sex, age, and the interaction between calendar year and region for the figures. The models were further adjusted for the interaction between calendar year and sex and age. The Pearson Chi-square test for goodness of fit was $>0.8$ for all models indicating appropriate fits.
All data management and analyses were performed in SAS, version 9.4 (SAS Institute Inc, Cary, NC, USA). A $p$-value $<0.05$ was defined as statistically significant.

\section{Ethics}

According to Danish legislation, approval from the Danish Health Research Ethics Committee System is not required for studies based solely on registers. Approval from the Danish Data Protection Agency was obtained for handling the data (journal number 2003-53-0865). All analyses were performed at servers at Statistics Denmark with pseudonymized personal identification numbers.

\section{Results}

The national incidence and prevalence rates of thyroid disease treatments per year are displayed in Table 1. The corresponding national incidence and prevalence RRs are displayed in Table S1.

\section{Antithyroid medication}

Incident antithyroid medication use increased above the rate in the year 2000 during the 2 years following IF but fell below since 2005 in the region with moderate ID before IF. In the

Table I National incidence and prevalence rates of treatments for thyroid diseases during 1995-20I5

\begin{tabular}{|c|c|c|c|c|c|c|}
\hline \multirow[t]{2}{*}{ Year } & \multicolumn{2}{|c|}{ Antithyroid medication } & \multicolumn{2}{|c|}{ Thyroid hormone therapy } & \multirow{2}{*}{$\begin{array}{l}\text { Thyroid } \\
\text { surgeries } \\
\text { Per } 100,000 \\
\text { persons }\end{array}$} & \multirow{2}{*}{$\begin{array}{l}\text { Radioiodine } \\
\text { treatments }^{\mathrm{a}} \\
\text { Per } 100,000 \\
\text { persons }\end{array}$} \\
\hline & $\begin{array}{l}\text { Incidence per } \\
\text { 100,000 PY }\end{array}$ & $\begin{array}{l}\text { Prevalence per } \\
100,000 \text { persons }\end{array}$ & $\begin{array}{l}\text { Incidence per } \\
\text { 100,000 PY }\end{array}$ & $\begin{array}{l}\text { Prevalence per } \\
100,000 \text { persons }\end{array}$ & & \\
\hline 1995 & - & 284.3 & - & 854.1 & 24.9 & 41.6 \\
\hline 1996 & - & 318.8 & - & 911.3 & 27.2 & 46.8 \\
\hline 1997 & 74.8 & 328.0 & 80.2 & 943.6 & 27.7 & 47.7 \\
\hline $1998^{b}$ & 81.9 & 342.5 & 84.6 & 983.9 & 27.9 & 48.1 \\
\hline 1999 & 86.1 & 361.2 & 95.6 & 1032.9 & 27.9 & 48.6 \\
\hline $2000^{c}$ & 94.1 & 384.1 & 98.3 & 1085.3 & 29.0 & 48.2 \\
\hline 2001 & 102.9 & 415.1 & 110.6 & 1146.0 & 27.2 & 50.1 \\
\hline 2002 & 98.7 & 434.3 & 114.0 & 1205.2 & 26.7 & 48.7 \\
\hline 2003 & 94.4 & 444.7 & 122.4 & 1269.8 & 27.0 & 46.1 \\
\hline 2004 & 82.7 & 441.7 & 118.0 & 1326.1 & 26.4 & 27.7 \\
\hline 2005 & 78.5 & 429.0 & 113.9 & 1369.1 & 28.2 & 29.3 \\
\hline 2006 & 73.5 & 418.4 & 128.9 & 1427.6 & 27.9 & 31.0 \\
\hline 2007 & 69.3 & 407.4 & 144.7 & | 494.1 & 28.3 & 34.2 \\
\hline 2008 & 68.8 & 398.4 & 146.8 & 1563.6 & 27.0 & 22.3 \\
\hline 2009 & 62.5 & 385.2 & 150.5 & 1631.1 & 32.0 & 25.1 \\
\hline 2010 & 61.5 & 374.9 & 158.0 & 1700.6 & 31.9 & 32.2 \\
\hline 2011 & 57.5 & 360.2 & 152.3 & 1760.4 & 31.7 & 34.0 \\
\hline 2012 & 59.5 & 354.1 & 146.2 & 1809.7 & 29.8 & 33.5 \\
\hline 2013 & 58.9 & 343.9 & 159.6 & 1865.2 & 31.9 & 30.7 \\
\hline 2014 & 57.7 & 336.8 & 159.9 & 1920.4 & 34.1 & 30.7 \\
\hline 2015 & - & - & - & - & 35.6 & 33.1 \\
\hline
\end{tabular}

Notes: Standardized for changes in population size, age, and sex distribution. aNumber of radioiodine treatment was obtained from the National Institute of Radiation Protection in 1995-2003 and from the Danish National Patient Registry in 2004-2015. 'lmplementation of voluntary iodine fortification. Implementation of mandatory iodine fortification in July 2000.

Abbreviation: PY, person years. 

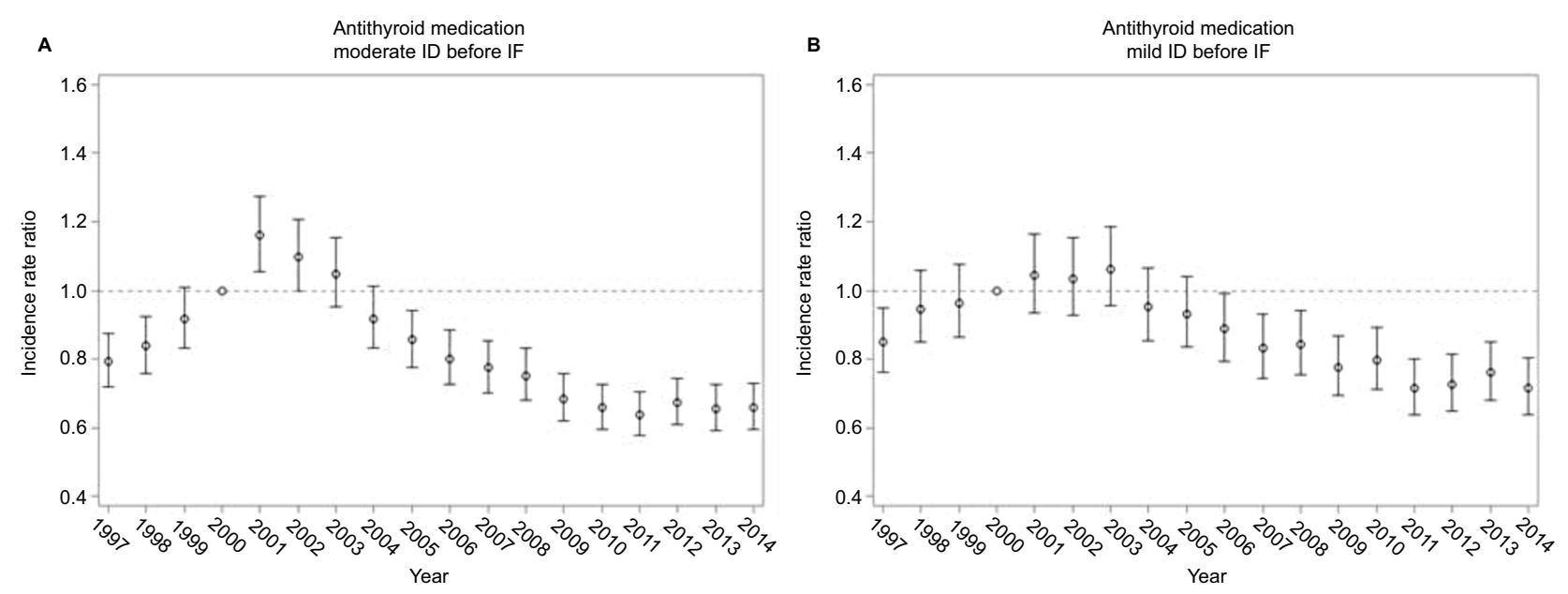

Figure I Incidence rate ratios and $95 \%$ confidence intervals of antithyroid medication compared to 2000 in (A) the region with moderate ID before IF and (B) the region with mild ID before IF.

Notes: The reference year is 2000 (implementation of IF). The analyses were adjusted for region, sex, age, and the interaction between calendar year and region.

Abbreviations: ID, iodine deficiency; IF, iodine fortification.
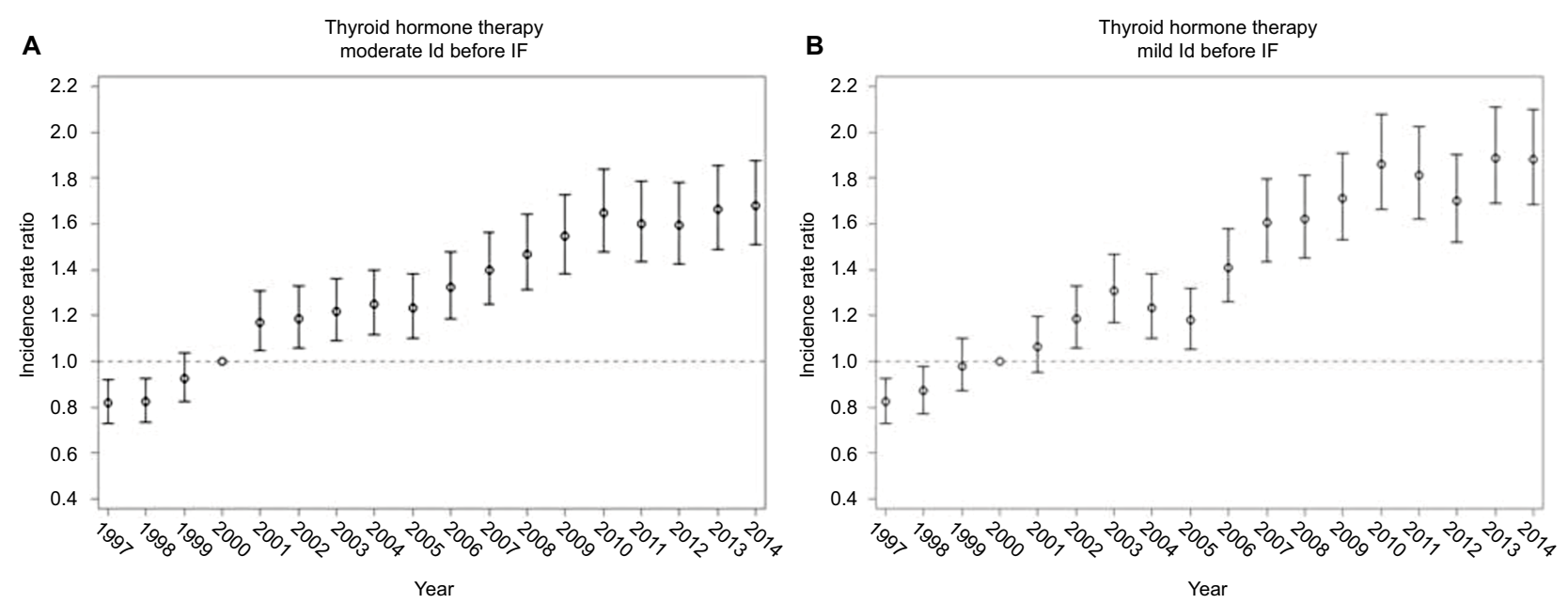

Figure 2 Incidence rate ratios and 95\% confidence intervals of thyroid hormone therapy compared to 2000 in (A) the region with moderate ID before IF and (B) the region with mild ID before IF.

Notes: The reference year is 2000 (implementation of IF). The analyses were adjusted for region, sex, age, and the interaction between calendar year and region.

Abbreviations: ID, iodine deficiency; IF, iodine fortification.

region with mild ID before IF, the incidence never rose significantly above the rate in the year 2000 and fell below since 2006. The incidence was constant since 2010-2011 in both regions (Figure 1). The incidence was higher in the region with moderate ID before IF, in women, and in the oldest age group, but these effects decreased over time (Figure S1).

Prevalent antithyroid medication use in both regions rose transiently above the rate in the year 2000 but decreased and was equal to the rate in the year 2000 since 2007-2008. The prevalence was higher in the region with moderate ID before IF, in women, and in the oldest age group (Figures S2 and S3).

\section{Thyroid hormone therapy}

Incident thyroid hormone therapy use increased during 19972009 and plateaued from 2010 in both regions (Figure 2). The incidence was equal in the regions, but higher in women and in the oldest age group. The difference between age groups decreased during the study period as the increase in incidence was largest below 65 years (Figure S4).

The prevalence increased almost linearly during the study period and did not differ between regions. The prevalence was higher in women and with increasing age (Figures S5 and S6). 


\section{Thyroid surgery}

In the region with moderate ID before IF, the rate of thyroid surgery was constant during the study period, but in the region with mild ID before IF the rate of surgery was higher in 2010, 2014, and 2015 vs. 2000 (Figure 3). The rate of thyroid surgery was significantly higher in the region with moderate ID before IF, in women, and in persons of 40-64 years. The increase in recent years was driven by an increase in persons of 65+ years ( Figure S7).

\section{Radioiodine treatment}

Trends in radioiodine treatment were evaluated from 2004. In the region with moderate ID before IF, rates of radioiodine treatment in 2006, 2007, and 2010-2015 were higher than in 2004. In the region with mild ID before IF, the rate was constant except for 2008 (Figures 4 and $\underline{\mathrm{S} 8}$ ). Both female sex and increasing age were associated with higher rates of radioiodine treatment. Only the effect of region changed over the years.

\section{Discussion}

Incidence of antithyroid medication increased, fell, and reached a steady state below the incidence at IF from 2010 to 2011. Incident thyroid hormone therapy increased until it reached a steady state in 2010 . For thyroid surgery, we observed an increase in recent years in the region with mild ID before IF. Whether this increase persists will require more years of observation. The rate of radioiodine treatment was overall constant with some fluctuations.

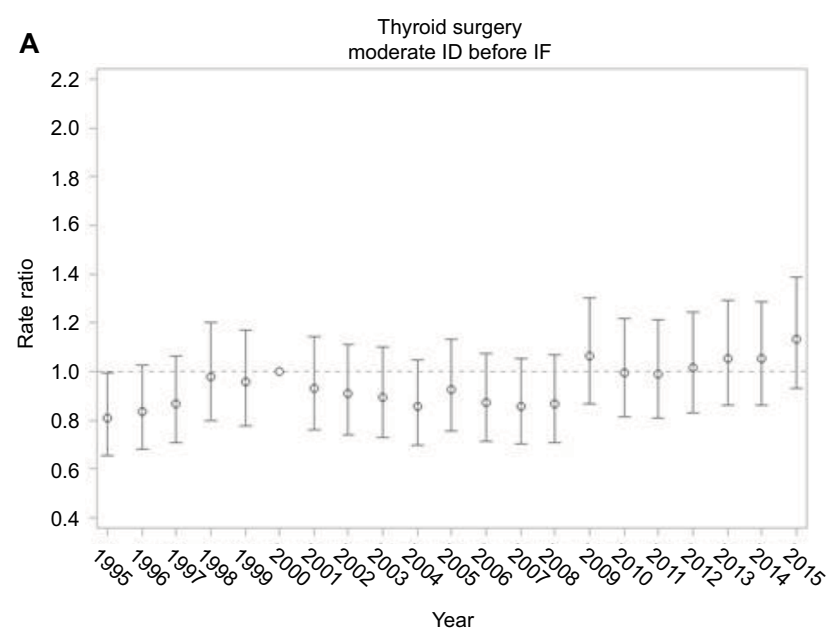

For antithyroid medication, the difference in incidence rates between regions, sexes, and age groups decreased during the study period. An aim of IF is prevention of ID-related diseases in vulnerable groups, that is, people in regions with ID, women, and young. ${ }^{2}$ As these groups obtain iodine sufficiency, region of residence, sex, and age are expected to have a smaller effect on disease outcomes, which is supported by our findings. Thyroid function is possibly affected by iodine intake throughout life, ${ }^{1}$ and thus, it is plausible that the full effect is not seen until the entire population has been iodine sufficient throughout life.

We expected the incidences of treatments to reflect incidences of thyroid diseases in concurrent Danish studies. A study based on laboratory databases from 1997 to 2004 also found a rise in incident hyperthyroidism, ${ }^{3}$ and two crosssectional studies in 1997-1998 and 2005 observed a decline in mild hyperthyroidism ${ }^{18}$ indicating trends parallel to our findings. The transient increase in hyperthyroidism after IF is well known and presumably a result of the higher prevalence of autonomous thyroid nodules or compensatory mechanisms in areas with ID, which will cause an overproduction of thyroid hormones after IF. Subsequent iodine sufficiency will lower the risk of autonomous thyroid nodules. ${ }^{1}$

The potential mechanisms behind a rise in hypothyroidism after IF are less clear. It is proposed that susceptible individuals may fail to escape the transient downregulation of iodine metabolism (ie, the Wolff-Chaikoff effect) after IF. 19,20 Also, IF has been proposed to enhance the risk of thyroid autoimmunity. ${ }^{21}$ Hypothyroidism is predominantly caused by autoimmune thyroid disease. ${ }^{22}$ The prevalence of positive

Figure 3 Incidence rate ratios and $95 \%$ confidence intervals of thyroid surgery compared to 2000 in (A) the region with moderate ID before IF and (B) the region with mild ID before IF.

Notes: The reference year is 2000 (implementation of IF). The analyses were adjusted for region, sex, age, and the interaction between calendar year and region. Abbreviations: ID, iodine deficiency; IF, iodine fortification. 

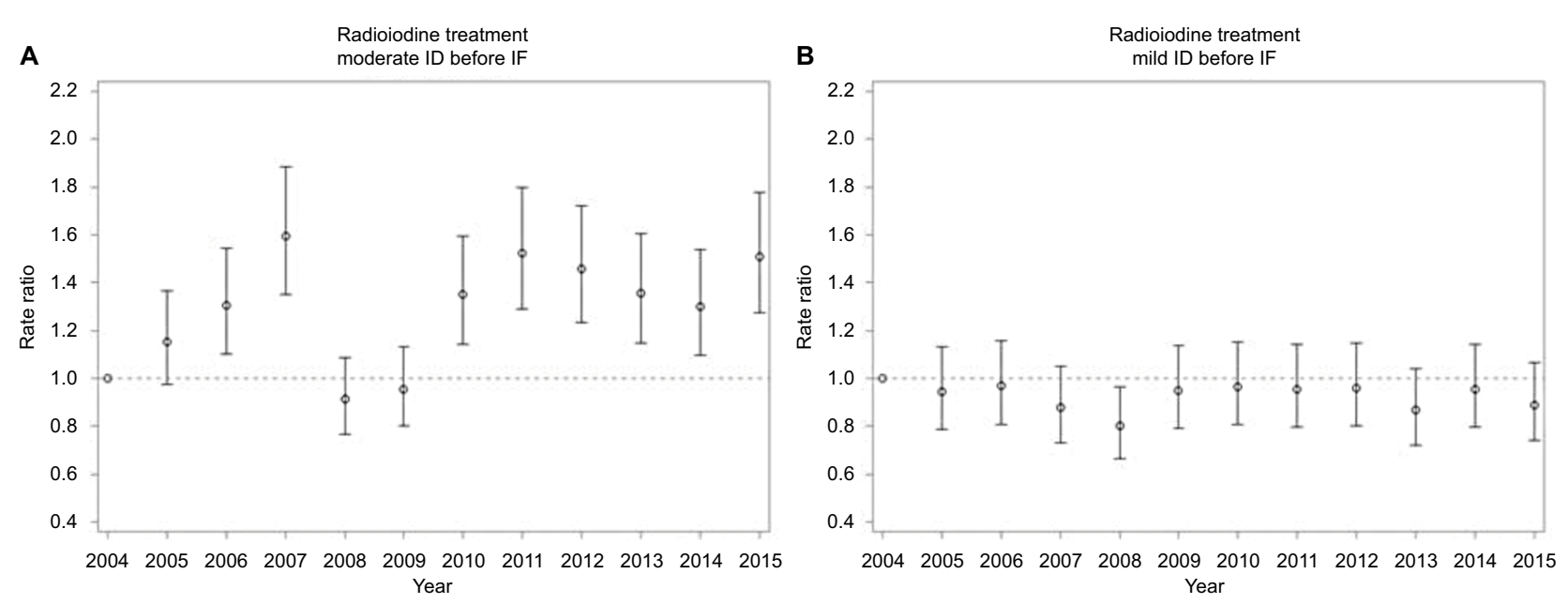

Figure 4 Incidence rate ratios and 95\% confidence intervals of radioiodine treatment compared to 2004 in (A) the region with moderate ID before IF and (B) the region with mild ID before IF.

Notes: The reference year is 2004 . The analyses were adjusted for region, sex, age, and the interaction between calendar year and region.

Abbreviations: ID, iodine deficiency; IF, iodine fortification.

thyroid autoantibodies increased from $20 \%$ in $1997-1998$ to $32 \%$ in 2004-2005 as shown in two cross-sectional studies, ${ }^{23}$ and a laboratory study found an incidence RR of hypothyroidism of 1.23 (95\% confidence interval 1.07-1.42) in 2003-2005 vs. 1997-1998 driven by an increase primarily in the region with moderate ID before IF and the younger age groups. ${ }^{5}$ This does not fully explain the steep increase in incident thyroid hormone therapy we observed in both regions and the oldest age group. Overall, goiters and nodules are treated with surgery and radioiodine depending on size and type. Between two cross-sectional studies in 1997-1998 and 2005, the prevalence of thyroid enlargement fell from $17.6 \%$ to $10.9 \% .{ }^{24}$ However, a longitudinal study from 1997 to 2008 saw both new appearances and disappearance of thyroid nodules. ${ }^{25}$ This contrasts the constant rate of thyroid surgery and radioiodine treatment we observed.

The diagnostic activity for thyroid diseases increased and the indication for some treatments may have changed during the study period, and thereby affected the treatment rates independently from changes in disease rates. The annual number of thyroid-stimulating hormone (TSH) measurements in the Copenhagen area increased by 164\% between 2011 and $2015,{ }^{26}$ and more ultrasound tests were performed in other countries and possibly also in Denmark. ${ }^{27,28}$ This could potentially lead to identification of more cases. We found no evidence to suggest that the indication for antithyroid medication treatment changed during the study period. In contrast, Medici et al found that the median TSH at initiation of thyroid hormone treatment decreased from $13 \mathrm{mIU} / \mathrm{L}$ to
$7.3 \mathrm{mIU} / \mathrm{L}$ during $2001-2015 .^{26}$ This explains a large proportion of the increase in rates of thyroid hormone treatment. In Denmark, enlarged thyroid was treated with radioiodine or surgery, and hyperthyroidism was treated with antithyroid medication, thyroid surgery, or radioiodine. ${ }^{29}$ However, the optimal treatment approach is not always clearly defined, and the preferred choice of treatment may have varied through the study period and differed between clinicians as observed in other countries, ${ }^{28}$ and could suggest why we do not see the expected decline in thyroid surgeries and radioiodine treatments.

The ecological study design increases the risk of confounding as it is difficult to isolate the effect of IF from temporal changes in confounders without individual-level data. Potential confounders, beside changes in treatment practices, include dietary iodine intake beyond IF, mineral interactions, alcohol consumption, smoking, and morbidities and medication that interfere with iodine or thyroid function. Two Danish cross-sectional studies found that low-adequate iodine intake was achieved following IF as median urinary iodine concentration rose from $61 \mu \mathrm{g} / \mathrm{L}$ in $1997-1998$ to $97-114 \mu \mathrm{g} / \mathrm{L}$ in $2004-2005 .{ }^{30}$ However, a follow-up of the first study in 2008-2010 found that this may not be sustained in women. ${ }^{30,31}$ Other minerals, especially selenium, are also essential for optimal thyroid function, and correction of ID may be futile if these are deficient. $^{32,33}$ This is not likely an issue in this study, as selenium deficiencies are rare in the Danish population. ${ }^{34}$ Alcohol consumption decreased in all age groups dur- 
ing the study period. ${ }^{35}$ The percentage of daily smokers decreased from 1994 to 2010 in all age groups, ${ }^{36}$ but this trend stagnated ${ }^{37}$ and smoking may be increasing in the youngest age group. ${ }^{38}$ This can potentially offset the beneficial effects for the first generation in Denmark to grow up in iodine sufficiency. Thyroid and gastrointestinal (GI) disorders are bidirectionally associated. Iodine malabsorption and reduced enterohepatic T3 reuptake are risk factors for hypothyroidism, and most thyroid diseases present with GI symptoms. ${ }^{39}$ We did not adjust for malabsorption because this is inadequately recorded in the registers and the direction of causality would be unclear. Lastly, some drugs may influence thyroid function, for example, lithium and amiodarone. ${ }^{40}$ The use of lithium in Denmark was relatively constant, while the use of amiodarone increased by roughly $10 \%$ during the study period. ${ }^{41}$ The potential effects on thyroid disease treatments may therefore be limited.

The main strength is the availability of complete registry data for all prescriptions and treatments in the total Danish population over 20 years, and the ability to adjust for individual-level demographic information. The Danish health registers have a high level of completeness and validity which has improved over the past 20 years. ${ }^{42}$ All medications studied require prescriptions, and therefore, a high level of completeness is expected. However, registration of radioiodine treatment in the National Patient Registry was introduced in 2004, and the registration may not have been fully accurate during the first years.

\section{Conclusion}

Ten years after IF, a steady state was observed for incident antithyroid medication below the level at IF, and thyroid hormone therapy above the level at IF. Only small changes were observed in thyroid surgery and radioiodine treatment. In the same period, changes in diagnostic and treatment practices and lifestyle factors are likely to have occurred and should be considered when evaluating effects of IF.

\section{Acknowledgments}

The authors acknowledge support from the DanThyr group. The study received financial support from Helsefonden. Also, this project received funding from the European Union's Horizon 2020 research and innovation program under grant agreement no. 634453. These organizations were not involved in the study conduct.

\section{Disclosure}

The authors report no conflicts of interest in this work.

\section{References}

1. Zimmermann MB, Boelaert K. Iodine deficiency and thyroid disorders. Lancet Diabetes Endocrinol. 2015;3(4):286-295.

2. World Health Organization. Guideline: Fortification of food-grade salt with iodine for the prevention and control of iodine deficiency disorders. Geneva: World Health Organization; 2014. Available from: http://www. who.int/nutrition/publications/guidelines/fortification_foodgrade_ saltwithiodine/en/. Accessed May 31, 2017.

3. Pedersen IB, Laurberg P, Knudsen N, et al. Increase in incidence of hyperthyroidism predominantly occurs in young people after iodine fortification of salt in Denmark. J Clin Endocrinol Metab. 2006;91(10): 3830-3834.

4. Bürgi H, Kohler M, Morselli B. Thyrotoxicosis incidence in Switzerland and benefit of improved iodine supply. Lancet. 1998;352(9133):1034.

5. Pedersen IB, Laurberg P, Knudsen N, et al. An increased incidence of overt hypothyroidism after iodine fortification of salt in Denmark: a prospective population study. J Clin Endocrinol Metab. 2007;92(8):3122-3127.

6. Aghini Lombardi F, Fiore E, Tonacchera M, et al. The effect of voluntary iodine prophylaxis in a small rural community: the Pescopagano survey 15 years later. J Clin Endocrinol Metab. 2013;98(3):1031-1039.

7. Petersen M, Carlé A, Knudsen NJ, et al. Iodine fortification only increased the incidence of overt hypothyroidism modestly - a 16 year Danish prospective population study. Poster presented at: The 40th Annual Meeting of the European Thyroid Association; September 9-12 2017; Belgrade.

8. Laurberg P, Jorgensen T, Perrild H, et al. The Danish investigation on iodine intake and thyroid disease, DanThyr: status and perspectives. Eur J Endocrinol. 2006;155(2):219-228.

9. Bekendtgørelse om tilsætning af jod til husholdningssalt og salt i brød og almindeligt bagværk m.v [Executive Order on the addition of iodine to household salt and salt in bread and ordinary baked goods, etc.] Fødevareministeriets bekendtgørelse nr. 6272000. Danish. Available from: https://www.retsinformation.dk/Forms/R0710.aspx?id=166747. Accessed June 28, 2017.

10. Rasmussen LB, Carle A, Jorgensen T, et al. Iodine intake before and after mandatory iodization in Denmark: results from the Danish Investigation of Iodine Intake and Thyroid Diseases (DanThyr) study. Br J Nutr. 2008;100(1):166-173.

11. Laurberg $P$, Cerqueira $C$, Ovesen L, et al. Iodine intake as a determinant of thyroid disorders in populations. Best Pract Res Clin Endocrinol Metab. 2010;24(1):13-27.

12. Cerqueira C, Knudsen N, Ovesen L, et al. Nationwide trends in surgery and radioiodine treatment for benign thyroid disease during iodization of salt. Eur J Endocrinol. 2010;162(4):755-762.

13. Cerqueira C, Knudsen N, Ovesen L, et al. Doubling in the use of thyroid hormone replacement therapy in Denmark: association to iodization of salt? Eur J Epidemiol. 2011;26(8):629-635.

14. Cerqueira C, Knudsen N, Ovesen L, et al. Association of iodine fortification with incident use of antithyroid medication - a Danish Nationwide Study. J Clin Endocrinol Metab. 2009;94(7):2400-2405.

15. Møllehave LT, Linneberg A, Skaaby T, et al. Trends in costs of thyroid disease treatment in Denmark during 1995-2015. Eur Thyroid J. 2018;7(2):75-83.

16. Andersen JS, Olivarius Nde F, Krasnik A. The Danish National Health Service Register. Scand J Public Health. 2011;39(7 Suppl):34-37.

17. Erlangsen A, Fedyszyn I. Danish nationwide registers for public health and health-related research. Scand J Public Health. 2015;43(4):333-339.

18. Vejbjerg P, Knudsen N, Perrild H, et al. Lower prevalence of mild hyperthyroidism related to a higher iodine intake in the population: prospective study of a mandatory iodization programme. Clin Endocrinol (Oxf). 2009;71(3):440-445.

19. McLachlan SM, Aliesky HA, Rapoport B. Aberrant iodine autoregulation induces hypothyroidism in a mouse strain in the absence of thyroid autoimmunity. J Endocr Soc. 2018;2(1):63-76.

20. Markou K, Georgopoulos N, Kyriazopoulou V, Vagenakis AG. Iodineinduced hypothyroidism. Thyroid. 2001;11(5):501-510. 
21. Safran M, Paul TL, Roti E, Braverman LE. Environmental factors affecting autoimmune thyroid disease. Endocrinol Metab Clin North Am. 1987;16(2):327-342.

22. Carlé A, Laurberg P, Pedersen IB, et al. Epidemiology of subtypes of hypothyroidism in Denmark. Eur J Endocrinol. 2006;154(1):21-28.

23. Pedersen IB, Knudsen N, Carle A, et al. A cautious iodization programme bringing iodine intake to a low recommended level is associated with an increase in the prevalence of thyroid autoantibodies in the population. Clin Endocrinol (Oxf). 2011;75(1):120-126.

24. Vejbjerg P, Knudsen N, Perrild H, et al. Effect of a mandatory iodization program on thyroid gland volume based on individuals' age, gender, and preceding severity of dietary iodine deficiency: a prospective, population-based study. J Clin Endocrinol Metab. 2007;92(4): 1397-1401.

25. Krejbjerg A, Bjergved L, Pedersen IB, et al. Thyroid nodules in an 11-year DanThyr follow-up study. J Clin Endocrinol Metab. 2014;99(12): 4749-4757.

26. Medici BB, Nygaard B, la Cour JL, et al. Changes in prescription practices when treating hypothyroidism between 2000 and 2015 - a register based study from the Copenhagen primary care laboratory (COPLAB) database. Poster presented at: The 40th Annual Meeting of the European Thyroid Association; September 9-12 2017; Belgrade.

27. Bartalena L, Burch HB, Burman KD, Kahaly GJ. A 2013 European survey of clinical practice patterns in the management of Graves' disease. Clin Endocrinol. 2016;84(1):115-120.

28. Burch HB, Burman KD, Cooper DS, Hennessey JV, Vietor NO. A 2015 survey of clinical practice patterns in the management of thyroid nodules. J Clin Endocrinol Metab. 2016;101(7):2853-2862.

29. Bonnema SJ, Bennedbaek FN, Wiersinga WM, Hegedus L. Management of the nontoxic multinodular goitre: a European questionnaire study. Clin Endocrinol (Oxf). 2000;53(1):5-12.

30. Rasmussen LB, Jørgensen T, Perrild H, et al. Mandatory iodine fortification of bread and salt increases iodine excretion in adults in Denmark - a 11-year follow-up study. Clin Nutr. 2014;33(6):1033-1040.

31. Rasmussen LB, Carlé A, Jørgensen T, et al. Iodine excretion has decreased in Denmark between 2004 and 2010 - the importance of iodine content in milk. Br J Nutr. 2014;112(12):1993-2001.

32. Köhrle J. Selenium and the thyroid. Curr Opin Endocrinol Diabetes Obes. 2015;22(5):392-401.
33. Zimmermann MB, Kohrle J. The impact of iron and selenium deficiencies on iodine and thyroid metabolism: biochemistry and relevance to public health. Thyroid. 2002;12(10):867-878.

34. Pedersen AN, Christensen T, Matthiessen J, et al. Danskernes kostvaner 2011-2013. Hovedresultater [Danish dietary habits 2011-2013. Main results]. Copenhagen: DTU Fødevareinstituttet; 2015. Danish. Available from: http://orbit.dtu.dk/files/110628064/Rapport_Danskernes_Kostvaner_2011_2013.pdf. Accessed March 23, 2018.

35. Alkoholstatistik 2015. Nationale data [Alcohol statistics 2015. National data]. Copenhagen: Sundhedsstyrelsen og Statens Serum Institut; 2015. Danish. Available from: https://www.sst.dk/da/udgivelser/2015/ / media/AD0E935AE31446C4AA09250B270A780B.ashx. Accessed October 10, 2017.

36. Christensen AI, Ekholm O, Davisen M, Juel K. Sundhed og sygelighed i Danmark 2010 - og udviklingen siden 1987 [Health and morbidity in Denmark 2010 - and development since 1987]. Copenhagen: Statens Institut for Folkesundhed, Syddansk Universitet; 2012. Danish. Available from: http://www.si-folkesundhed.dk/upload/susy_2010_til_hjemmeside.pdf. Accessed October 10, 2017.

37. Danskernes rygevaner 2016 [Danes' smoking habits 2016]. Copenhagen: Sundhedsstyrelsen; 2016. Danish. Available from: https://www.sst. $\mathrm{dk} / \mathrm{da} /$ sundhed-og-livsstil/tobak/tal-og-fakta/danskernes-rygevaner/ / media/4E2B6AA5E7BB4DFAA9341F1ECF1FF353.ashx. Accessed October 10, 2017.

38. Kræftens Bekæmpelse. Flere unge ryger [More young people smoke] [press release]. Copenhagen: Kræftens Bekæmpelse; 2017 [March 4]. Danish. Available from: https://www.cancer.dk/nyheder/flere-ungeryger/. Accessed October 11, 2017.

39. Kyriacou A, McLaughlin J, Syed AA. Thyroid disorders and gastrointestinal and liver dysfunction: a state of the art review. Eur J Intern Med. 2015;26(8):563-571.

40. Kundra P, Burman KD. The effect of medications on thyroid function tests. Med Clin North Am. 2012;96(2):283-295.

41. Medstat.dk [homepage on the Internet]. Copenhagen: Sundhedsdatastyrelsen. Available from: http://www.medstat.dk/. Accessed March 23, 2018. Danish

42. Schmidt M, Schmidt SA, Sandegaard JL, Ehrenstein V, Pedersen L, Sorensen HT. The Danish National Patient Registry: a review of content, data quality, and research potential. Clin Epidemiol. 2015;7:449-490.
Clinical Epidemiology

\section{Publish your work in this journal}

Clinical Epidemiology is an international, peer-reviewed, open access, online journal focusing on disease and drug epidemiology, identification of risk factors and screening procedures to develop optimal preventative initiatives and programs. Specific topics include: diagnosis, prognosis, treatment, screening, prevention, risk factor modification,

Submit your manuscript here: https://www.dovepress.com/clinical-epidemiology-journa

\section{Dovepress}

systematic reviews, risk and safety of medical interventions, epidemiology and biostatistical methods, and evaluation of guidelines, translational medicine, health policies and economic evaluations. The manuscript management system is completely online and includes a very quick and fair peer-review system, which is all easy to use. 